\title{
STUDIO SULLA PRESENZA DI VIRUS DERMOTROPI IN PRELIEVI DI CUTE DESTINATI A TRAPIANTO.
}

Scarasciulli ML.', Calvario A. ${ }^{2}$, Bozzi A.', Dilonardo A.', Satalino M. ${ }^{2}$, Dammacco MA.', Dioguardi D.'

'Dipartimento di Applicazioni In Chirurgia di Tecnologie Innovative (DACTI), Sez. Chirurgia Plastica Università degli Studi - Policlinico Bari. ${ }^{2}$ Laboratorio di Virologia, U.O. Igiene, Epidemiologia e Sanità Pubblica II - A.O. Policlinico Bari.

\section{Introduzione}

Nonostante i progressi compiuti in trapiantologia, le infezioni da herpesvirus restano la causa maggiore di morbidità e mortalità nei pazienti trapiantati, spesso indipendentemente dallo specifico stato anticorpale.

L'obiettivo dello studio è valutare la presenza di virus dermotropi HSV1, HSV2, CMV, EBV, VZV, HHV6 e HHV8 nei trapianti di tessuto cutaneo.

\section{Materiali e metodi}

Previo consenso informato, sono stati arruolati 10 pazienti sani, ospedalizzati presso l'U.O. Chirurgia Plastica Universitaria Policlinico di Bari da sottoporre a chirurgia ricostruttiva, selezionati secondo i criteri dei donatori multiorgano. Da ciascun paziente, noto lo stato immunologico di base (fatta eccezione per HHV6 e HHV8), in fase pre-operatoria, sono stati raccolti siero, PBL, gargarizzato e urine destinati alla ricerca molecolare con tecnica PCR Nested e PCR Real Time.

In sede operatoria, dagli stessi pazienti sono stati prelevati 3 
lembi di cute $(3 \times 5 \mathrm{~cm})$ da materiale chirurgico di scarto, bioptizzati (biopsy punch $\varnothing 8 \mathrm{~mm}$ ) e avviati, in parallelo, ad indagini colturali e di biologia molecolare per la ricerca di DNA virale. Estrazione, amplificazione e rivelazione del DNA è stata condotta secondo i protocolli forniti dal produttore (Amplimedical Diagnostic Group srl).

\section{Risultati e conclusioni}

Tutti i 10 pazienti, di sesso femminile, sono risultati immuni e 9 positivi per HSV1e/o HSV2 (3 positivi HSV1/2, 3 positivi HSV2, 3 positivi HSV1) in vari distretti corporei e precisamente:

- 7 su cute; tra questi, 4 presentavano positività anche su PBLs; - 2 su siero, PBLs e gargarizzato.

In 6 pazienti è stata rilevata la presenza di HHV8: su siero e PBLs in 3 pazienti (di cui positivo anche su gargarizzato e cute); su PBLs e cute in 1 caso, su gargarizzato in 1 paziente, solo su PBLs in 1 altro.

Degno di nota un caso di positività per VZV riscontrata in triplo su cute.

La positività di virus dermotropi ritrovati su cute potrebbe essere spiegata con la tendenza a migrare dai gangli e colonizzare le cellule epiteliali della porzione media (infundibolo e istmo) del follicolo (Muraki, 1996), proprio in quella regione che è compresa nei prelievi di cute a tutto spessore utilizzati nei trapianti. Tale riscontro suggerirebbe l'ipotesi di rischio di trasmissione virale mediante trapianto di cute allogenica. 